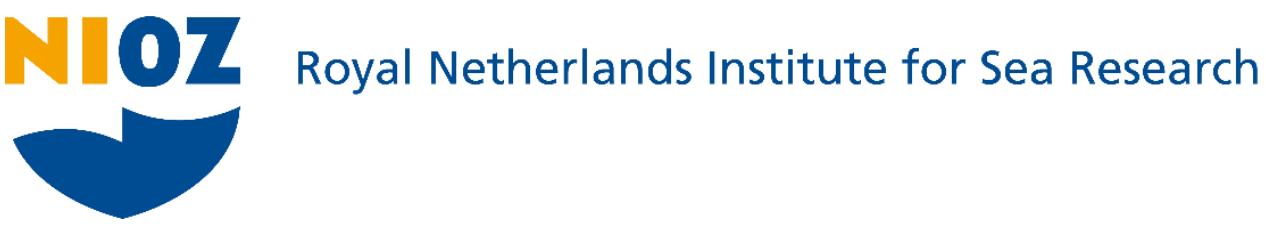

This is a pre-copyedited, author-produced version of an article accepted for publication, following peer review.

Kraal, P.; van Genuchten, C.M.; Behrends, T. \& Rose, A.L. (2019). Sorption of phosphate and silicate alters dissolution kinetics of poorly crystalline iron (oxyhydr)oxide. Chemosphere, 234, 690-701

Published version: https://dx.doi.org/10.1016/i.chemosphere.2019.06.071

NIOZ Repository: http://imis.nioz.nl/imis.php?module=ref\&refid=317614

[Article begins on next page]

The NIOZ Repository gives free access to the digital collection of the work of the Royal Netherlands Institute for Sea Research. This archive is managed according to the principles of the Open Access Movement, and the Open Archive Initiative. Each publication should be cited to its original source - please use the reference as presented.

When using parts of, or whole publications in your own work, permission from the author(s) or copyright holder(s) is always needed. 


\title{
Sorption of phosphate and silicate alters dissolution kinetics of poorly crystalline iron (oxyhydr)oxide
}

\author{
Peter Kraal $^{\mathrm{a}, \mathrm{b}^{*}}$, Case M. van Genuchten ${ }^{\mathrm{a}}$, Thilo Behrends ${ }^{\mathrm{a}}$, Andrew L. Rose ${ }^{\mathrm{c}}$
}

${ }^{\text {a }}$ Department of Earth Sciences - Geochemistry, Faculty of Geosciences, Utrecht University, PO Box 80021, 3508 TA Utrecht, The Netherlands

${ }^{\mathrm{b}}$ Royal Netherlands Institute for Sea Research, Department of Ocean Systems, and Utrecht University, P.O. Box 59, 1790 AB Den Burg, The Netherlands

${ }^{\mathrm{c}}$ School of Environment, Science and Engineering, Southern Cross University, PO Box 157, Lismore NSW, Australia

* Corresponding author, email: peter.kraal@nioz.nl 


\begin{abstract}
Iron (oxyhydr)oxides (FeOx) control retention of dissolved nutrients and contaminants in aquatic systems. However, $\mathrm{FeOx}$ structure and reactivity is dependent on adsorption and incorporation of such dissolved species, particularly oxyanions such as phosphate and silicate. These interactions affect the fate of nutrients and metal(loids), especially in perturbed aquatic environments such as eutrophic coastal systems and environments impacted by acid mine drainage. Altered $\mathrm{FeOx}$ reactivity impacts sedimentary nutrient retention capacity and, eventually, ecosystem trophic state. Here, we explore the influence of phosphate (P) and silicate $(\mathrm{Si})$ on $\mathrm{FeOx}$ structure and reactivity. Synthetic, poorly crystalline FeOx with adsorbed and coprecipitated phosphate or silicate at low but environmentally relevant $\mathrm{P} / \mathrm{Fe}$ or $\mathrm{Si} / \mathrm{Fe}$ ratios $\left(0.02-0.1 \mathrm{~mol} \mathrm{~mol}^{-1}\right)$ was prepared by base titration of $\mathrm{Fe}(\mathrm{III})$ solutions. Structural characteristics of FeOx were investigated by X-ray diffraction, synchrotron-based X-ray absorption spectroscopy and high-energy X-ray scattering. Reactivity of FeOx was assessed by kinetic dissolution experiments under acidic (dilute $\mathrm{HCl}, \mathrm{pH} 2$ ) and circumneutral reducing (bicarbonate-buffered ascorbic acid, $\mathrm{pH} 7.8, E_{h} \sim-300 \mathrm{mV}$ ) conditions. At these loadings, phosphate and silicate coprecipitation had only slight impact on local and intermediate-ranged $\mathrm{FeOx}$ structure, but significantly enhanced the dissolution rate of $\mathrm{FeOx}$. Conversely, phosphate and silicate adsorption at similar loadings resulted in particle surface passivation and decreased $\mathrm{FeOx}$ dissolution rates. These findings indicate that varying nutrient loadings and different interaction mechanisms between anions and $\mathrm{FeOx}$ (adsorption versus coprecipitation) can influence the broader biogeochemical functioning of aquatic ecosystems by impacting the structure and reactivity of FeOx.
\end{abstract}




\section{Introduction}

Iron minerals such as ferric iron (oxyhydr)oxides (here, referred to as $\mathrm{FeOx}$ ), play a crucial role in the biogeochemical cycling and mobility of nutrients, trace elements and contaminants in aquatic systems. Ferrihydrite $(\mathrm{Fh}), \mathrm{Fe}_{10} \mathrm{O}_{14}(\mathrm{OH})_{2} \cdot \mathrm{nH}_{2} \mathrm{O}$ with $\mathrm{n}<1$ according to the most recent model (Michel et al., 2007; Hiemstra, 2013), is a particularly reactive $\mathrm{FeOx}$ that forms in soils and sediments by rapid $\mathrm{Fe}^{2+}$ oxidation or $\mathrm{Fe}^{3+}$ hydrolysis (Jambor and Dutrizac, 1998). Although Fh is thermodynamically unstable, its crystallization to more stable phases such as lepidocrocite and goethite can be inhibited in the presence of anions and organic compounds (Schwertmann and Cornell, 1991; Jones et al., 2009; Voegelin et al., 2013; Senn et al., 2017). Ferrihydrite has a high affinity for sorption of oxyanions of arsenic (As), phosphorus (P) and silicate ( $\mathrm{Si}$ ), which are environmentally significant as nutrients and/or contaminants. Consequently, Fh plays an important role in (i) scavenging and retention of nutrients in freshwater and marine systems (Buffle et al., 1989; Norkko et al., 2012), and (ii) retardation of toxic metal(loid) transport in surface waters that are contaminated by mining activities (Rose and Ghazi, 1998; Webster et al., 1998).

Interaction with oxyanions in solution can alter the structure and reactivity of Fh (Waychunas et al., 1993; Paige et al., 1997b; Majzlan, 2011) either through adsorption (binding of oxyanions onto pre-existing Fh surfaces) and coprecipitation (FeOx nucleation and particle growth in the presence of oxyanions). Adsorption of oxyanions has a relatively minor effect on FeOx mineral structure (Waychunas et al., 1993; van Genuchten and Peña, 2016), but decreases mineral reactivity and solubility by forming multi-nuclear inner-sphere complexes with surface groups (Biber et al., 1994; Stumm, 1997). This can thermodynamically stabilize the Fh surface (Majzlan, 2011) and retard the crystallization of Fh to goethite and hematite (Cornell et al., 1987; Paige et al., 1997b). Furthermore, adsorption of phosphate onto Fh at concentrations sufficient to saturate surface sites has been 
shown to lead to a three-fold decrease in the Fh reduction rate by the bacterium Shewanella putrefaciens (CN32) in microbial incubation experiments (Borch et al., 2007). In a recent study, a marked decrease in the rate and extent of microbially-mediated reductive dissolution of schwertmannite, a poorly ordered Fe(III) oxyhydroxysulfate, with increasing P surface coverage was observed (Schoepfer et al., 2017). The stabilization of the FeOx surface by oxyanion sorption and subsequent decrease in the rate of reductive Fe dissolution may modulate benthic Fe release and thus affect Fe availability in aquatic systems.

Coprecipitation differs from adsorption in that oxyanions interact with $\mathrm{Fe}$ polyhedra during nucleation and thereby alter the final mineral structure. Increased disorder of $\mathrm{FeOx}$ formed in the presence of oxyanions such as $\mathrm{AsO}_{4}$, phosphate and silicate has been observed during rapid $\mathrm{Fe}(\mathrm{III})$ hydrolysis in highly concentrated $\left(\sim 0.5 \mathrm{~mol} \mathrm{~L}^{-1}\right) \mathrm{Fe}(\mathrm{III})$ solutions (Waychunas et al., 1993; Rose et al., 1996) as well as during oxygenation of less concentrated $\left(<1 \mathrm{~m} \mathrm{~mol} \mathrm{~L}^{-1}\right) \mathrm{Fe}(\mathrm{II})$ solutions (Voegelin et al., 2010; van Genuchten et al., 2014; Senn et al., 2015; Senn et al., 2017). Occupation of FeOx surface sites by P or Si disrupts $\mathrm{Fe}-\mathrm{Fe}$ polymerization and leads to the formation of relatively small, poorly ordered FeOx polymers with relatively large surface areas. Decreased order, greater surface area and difference in particle charge suggest that oxyanion coprecipitation would enhance the reactivity and solubility of Fh. Indeed, Kukkadapu et al. (2004) found that incorporation of even small amounts of $\mathrm{Si}$ in $\mathrm{Fh}\left(\mathrm{Si} /(\mathrm{Si}+\mathrm{Fe})=0.01-0.05 \mathrm{~mol} \mathrm{~mol}^{-1}\right)$ increased the extent of Fh reduction by Shewanella putrefaciens over 1 week about 5-fold. Conversely, coprecipitation of oxyanions such as arsenate $\left(\mathrm{AsO}_{4}\right)$, phosphate and silicate has been shown to strongly inhibit the crystallization of Fh (Cornell et al., 1987; Paige et al., 1997b; Senn et al., 2017). Furthermore, Paige et al. (1997a) reported that As coprecipitation decreased the rate of Fh dissolution under acidic conditions. As such, the stabilizing effect of adsorption of 
oxyanions onto the FeOx surface seems well-established, but the impact of oxyanion coprecipitation on $\mathrm{FeOx}$ reactivity is not well understood.

Here, we investigate the impact of the adsorption and coprecipitation of phosphate and silicate on the structure and dissolution kinetics of $\mathrm{FeOx}$, formed by base titration of $\mathrm{Fe}(\mathrm{III})$ solutions, under acidic $(\mathrm{pH} 2)$ and circum-neutral ( $\mathrm{pH}$ 7.8) reducing conditions. Our results show a subtle impact of oxyanion coprecipitation on FeOx structure, but marked and opposite effects of adsorption and coprecipitation on the rate of $\mathrm{FeOx}$ dissolution.

\section{Materials and methods}

\subsection{Synthesis of $2 L-F h$}

Pure two-line ferrihydrite (2L-Fh, denoted here as pure FeOx) was synthesized following the procedure of Schwertmann and Cornell (1991) with $\mathrm{NaOH}$ as base. In short, $40 \mathrm{~g}$ of $\mathrm{Fe}(\mathrm{III})\left(\mathrm{NO}_{3}\right)_{3} \cdot 9 \mathrm{H}_{2} \mathrm{O}$ (Merck EMSURE) was dissolved in $500 \mathrm{~mL}$ degassed ultrapure $\mathrm{H}_{2} \mathrm{O}$ (initial Fe concentration $\sim 0.2 \mathrm{~mol} \mathrm{~L}^{-1}$ ) in a HDPE beaker and the $\mathrm{pH}$ was subsequently brought to a stable value of 7.5 with $1 \mathrm{~mol} \mathrm{~L}^{-1} \mathrm{NaOH}$ that was titrated at a maximum rate of

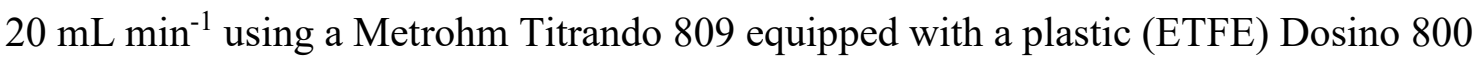
burette. The $\mathrm{pH}$ was considered stable when $\Delta \mathrm{pH}<0.01$ over a 10 -minute period. The total volume of added $1 \mathrm{~mol} \mathrm{~L}^{-1} \mathrm{NaOH}$ was $\sim 330 \mathrm{~mL}$. The suspension was bubbled with $\mathrm{Ar}$ throughout the synthesis procedure to avoid the introduction of $\mathrm{CO}_{2}$. The precipitate was transferred into Spectra/Por 4 regenerated cellulose dialysis tubing (SpectrumLabs) and dialyzed in $10 \mathrm{~L}$ of ultrapure water with regular water changes until the electric conductivity was $<10 \mu \mathrm{S} \mathrm{cm}^{-1}$ (4 days). 


\subsection{Silicate and phosphate sorption curves}

Sorption of $\mathrm{P}$ and Si onto 2L-Fh was examined at pH 6, 7 and 8 using a 13-point concentration gradient over the range $0-2500 \mu \mathrm{mol} \mathrm{P}$ or Si $\mathrm{L}^{-1}$ at each $\mathrm{pH}$. The data were fit using the Freundlich and Langmuir equations. More information on chemical and experimental conditions for the sorption curves can be found in the supplementary information.

\subsection{Synthesis of $2 \mathrm{L-Fh}$ with adsorbed phosphate or silicate}

Two-line ferrihydrite with phosphate or silicate adsorbed to the mineral surface (denoted as $\mathrm{P}$-ads $\mathrm{FeOx}$ and $\mathrm{Si}$-ads $\mathrm{FeOx}$, respectively) was prepared by addition of $\mathrm{P}$ or $\mathrm{Si}$ to the dialyzed 2L-Fh suspension as follows. Four separate experiments were conducted to obtain 2L-Fh with "high" and "low" P or Si surface loading (Table 1), roughly corresponding to $25 \%$ and $65 \%$ surface coverage assuming the asymptotic maxima of the P and Si sorption curves (Fig. S1) represent saturation of surface sites. Due to the lower adsorption maximum of Fh for Si compared to $\mathrm{P}$, the $\mathrm{Si} / \mathrm{Fe}$ ratios corresponding to low and high $\mathrm{Si}$ loading are lower than the $\mathrm{P} / \mathrm{Fe}$ ratios. In LDPE bottles, $15 \mathrm{~mL}$ of the pure $2 \mathrm{~L}-\mathrm{Fh}$ suspension was added to $500 \mathrm{~mL}$ of degassed $0.7 \mathrm{~mol} \mathrm{~L}^{-1} \mathrm{NaCl}$ with an appropriate concentration of sodium phosphate $\left(\mathrm{Na}_{2} \mathrm{HPO}_{4} \cdot 7 \mathrm{H}_{2} \mathrm{O}\right)$ or sodium metasilicate $\left(\mathrm{Na}_{2} \mathrm{SiO}_{3} \cdot 9 \mathrm{H}_{2} \mathrm{O}\right)$. The $\mathrm{pH}$ was measured with a calibrated Orion glass $\mathrm{pH}$ electrode and adjusted to 7 with small additions of concentrated $\mathrm{HCl}$ or $\mathrm{NaOH}$. The suspensions were shaken horizontally at $100 \mathrm{rpm}$ for $92 \mathrm{~h}$ ( $\mathrm{pH}$ readjusted after $48 \mathrm{~h}$ ), after which the suspensions were allowed to settle for $2 \mathrm{~h}$ and the clear supernatant was decanted. The remaining suspension was transferred into $50 \mathrm{~mL}$ polypropylene tubes, which were centrifuged at $2500 \mathrm{rpm}$ for $5 \mathrm{~min}$, after which the supernatant was decanted. The resulting slurries were washed three times by resuspension in 
$250 \mathrm{~mL} 0.7 \mathrm{~mol} \mathrm{~L}^{-1} \mathrm{NaCl}$ followed by centrifugation and decantation, and afterwards resuspended in $15 \mathrm{~mL} 0.7 \mathrm{~mol} \mathrm{~L}^{-1} \mathrm{NaCl}$ to obtain the original suspension density.

FeOx with coprecipitated $\mathrm{P}$ or $\mathrm{Si}$ was synthesized by rapid hydrolysis of $\mathrm{Fe}(\mathrm{III})$ in the presence of P or Si. For consistency in the manuscript, we refer to these species as P-cop $\mathrm{FeOx}$ and $\mathrm{Si}$-cop $\mathrm{FeOx}$. These $\mathrm{FeOx}$ were prepared with target molar $\mathrm{P} / \mathrm{Fe}$ or $\mathrm{Si} / \mathrm{Fe}$ ratios of $1 / 10$ and $1 / 20$, respectively (Table 1). For this, appropriate amounts of $\mathrm{Na}_{2} \mathrm{HPO}_{4} \cdot 7 \mathrm{H}_{2} \mathrm{O}$ or $\mathrm{Na}_{2} \mathrm{SiO}_{3} \cdot 9 \mathrm{H}_{2} \mathrm{O}$ were added to the degassed $1 \mathrm{~mol} \mathrm{~L}^{-1} \mathrm{NaOH}$ solutions prior to $\mathrm{Fe}(\mathrm{III})$ hydrolysis by base titration. The various precipitates were dialyzed in separate water baths and stored in suspension in the dark at $4{ }^{\circ} \mathrm{C}$. The dissolution experiments (section 2.4) started immediately after synthesis of all required minerals. The final concentration in all

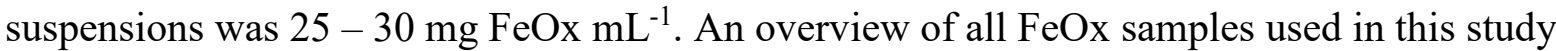
is given in Table 1.

\subsection{Characterization of FeOx}

From all FeOx suspensions, a subsample was freeze-dried and ground immediately after dialysis. For regular 2L-Fh, another subsample was freeze-dried after $\sim 4$ weeks of storage ("aged" 2L-Fh) to check for aging effects. In addition, a $\sim 10 \mathrm{mg}$ subsample of each FeOx was dissolved in $1 \mathrm{~mL}$ concentrated suprapur $\mathrm{HCl}$ overnight with subsequent 10 -fold dilution with ultrapure $\mathrm{H}_{2} \mathrm{O}$ for measurements of $\mathrm{Fe}, \mathrm{P}$ and $\mathrm{Si}$. The Fe contents of the acid digests were determined colorimetrically by the 1,10-phenanthroline (Fe) (APHA, 2005), P or Si content were quantified using the molybdenum blue method (Mullin and Riley, 1955; Strickland and Parsons, 1972). Absorbance was measured with a Shimadzu UV-1800 spectrophotometer.

Subsamples of the freeze-dried and ground FeOx were analyzed with a Bruker-AXS D2 Phaser powder X-ray diffractometer equipped with Lynxeye detector and Cobalt $\mathrm{K} \alpha_{1,2}$ 
radiation source. For Fe K-edge extended X-ray absorption fine structure (EXAFS) spectroscopy measurements, a second series of subsamples of the freeze-dried and ground FeOx was thoroughly mixed with small quantities of microcrystalline cellulose (Sigma Aldrich) by manual grinding with an agate mortar and pestle. Part of the mixture, containing the amount of sample for which Fe absorption was about 1 absorption length (Kelly et al., 2008), was pressed into $7 \mathrm{~mm}$-diameter pellets (thickness $\sim 1 \mathrm{~mm}$ ) using a hand-held hydraulic pellet press (Pike Technologies). The pellets were transported to the European Synchrotron Radiation Facility (ESRF) in Grenoble (France) to collect Fe K-edge EXAFS spectra at beamline BM26A (DUBBLE). Details on the beamline setup can be found in Borsboom et al. (1998) and Nikitenko et al. (2008). At the beamline, the pellets were sealed between two layers of Kapton tape and mounted onto the sample holder. Spectra were recorded at room temperature in transmission mode from 6962 to $7862 \mathrm{eV}$, corresponding to a maximum $k$ of $13 \AA^{-1}$ in the EXAFS region. The vertical dimension of the X-ray beam was $1 \mathrm{~mm}$, the horizontal dimension was $3 \mathrm{~mm}$ and the X-ray beam was detuned $30 \%$ to prevent second-order harmonics. The near-edge X-ray absorption (XANES) region was measured with $0.35 \mathrm{eV}$ steps, whereas step sizes of $0.05 \AA^{-1}$ were used for the EXAFS region. Two scans were collected for each sample. A Fe(0) foil was used to calibrate the energy of the beam by adjusting the maximum slope of the Fe main edge to $7112 \mathrm{eV}$. Spectra were averaged, and background-subtracted using the software package Athena (Ravel and Newville, 2005). The EXAFS spectra were extracted using $k^{3}$-weighting and were Fouriertransformed over the $k$-range $2-11 \AA^{-1}$ using a Kaiser-Bessel window with dk of $3 \AA^{-1}$. Spectra were compared to those of Fe reference materials collected during previous synchrotron visits (Kraal et al., 2017).

For the collection of high-energy X-ray scattering (HEXS) data suitable for pair distribution function (PDF) analysis, a third series of subsamples were ground using an agate 
mortar and pestle and loaded into Kapton capillaries. HEXS data were collected at room temperature at beamline 11-ID-B of the Advanced Photon Source (APS) at Argonne National Laboratory (Argonne, Illinois, USA). The X-ray energy during data collection was $58.9 \mathrm{keV}$ and data were collected out to a $Q$ value near $29 \AA^{-1}$. Scattering patterns were corrected for sample-to-detector distance, tilt angle of the detector with respect to the direction of the incident beam, and X-ray polarization and integrated radially using the Fit2D program (Hammersley et al., 1996). The PDFGetX2 program (Farrow et al. 2007) was used to extract the total structure function (S(Q)) and the PDF $(\mathrm{G}(\mathrm{r}))$ using standard procedures (Chupas et al., 2003).

\subsection{Acidic and reductive dissolution experiments}

The dissolution kinetics of the various synthesized $\mathrm{FeOx}$ was studied under acidic ( $\mathrm{pH} 2$ ) conditions (acidic dissolution experiment; ADE) and circum-neutral ( $\mathrm{pH} 7.8)$ reducing conditions (reductive dissolution experiment; RDE). The dissolution experiments were performed using polyethylene terephthalate (PET) bottles and included duplicates for each FeOx. The samples were divided over four experimental runs in the order: ADE P-bearing FeOx, ADE Si-bearing FeOx, RDE P-bearing FeOx, RDE Si-bearing FeOx. All four runs included 2L-Fh as reference. Runs were started consecutively with two-week intervals. Total $\mathrm{Fe}, \mathrm{P}$ and Si concentrations in the ADE and RDE were determined colorimetrically in unfiltered samples from the PET bottles that were taken after thorough homogenization and acidified to $\mathrm{pH} 0$ for $16 \mathrm{~h}$ in order to dissolve all $\mathrm{FeOx}$.

For the ADE, $2 \mathrm{~mL}$ of FeOx suspension ( $\sim 50 \mathrm{mg} F \mathrm{Fex})$ was introduced into $500 \mathrm{~mL}$ of $0.01 \mathrm{~mol} \mathrm{~L}^{-1}$ suprapur $\mathrm{HCl}(\mathrm{pH} 2)$. The $\mathrm{pH}$ was checked regularly throughout the experiment and did not deviate significantly from the target value of 2 . The suspensions were continuously stirred by Teflon-coated floating stir bars on an IKA RO15 magnetic stirrer 
(400 rpm). After set time intervals, a $2 \mathrm{~mL}$ sample was taken from each bottle using a $10 \mathrm{~mL}$ syringe and filtered over $0.2 \mu \mathrm{m}$ Nylon filter membranes. A $500 \mu \mathrm{L}$ subsample of this filtrate was immediately brought to $\mathrm{pH} 4 \mathrm{using} 500 \mu \mathrm{L}$ of $3 \mathrm{~mol} \mathrm{~L}^{-1}$ acetic acid/3 mol L-1 sodium acetate in polystyrene cuvette, in order to slow down acidic dissolution. Preliminary experiments had shown negligible $\mathrm{FeOx}$ dissolution at $\mathrm{pH} 4$ over several days. The light absorbance of this mixture at $430 \mathrm{~nm}$ was recorded. Immediately afterwards, $25 \mu \mathrm{L}$ of a 5 mM stock of the selective Fe(III) chelator desferrioxamine B (DFO-B, Sigma Aldrich) was added and after 10 minutes the light absorbance was again measured at $430 \mathrm{~nm}$. Preliminary testing has shown that this time period was required for complete reaction between dissolved Fe(III) and DFO-B in solutions of similar chemical composition. Desferrioxamine B binds dissolved and weakly complexed Fe(III) in seconds to minutes, while it binds more strongly complexed Fe on longer timescales (hours) (Pham et al., 2006). The absorbance measured after 10 min was used as a measure of the pool of dissolved and weakly complexed Fe(III) in the filtrates, denoted here as Fe(III) dissolved. After $72 \mathrm{~h}$, the final absorbance value in the DFOB samples was used as measure for total $\mathrm{Fe}(\mathrm{III})<0.2 \mu \mathrm{m}$ in the filtrates, denoted as $\mathrm{Fe}(\mathrm{III})<0.2 \mu \mathrm{m}$. The difference between $\mathrm{Fe}(\mathrm{III})<0.2 \mu \mathrm{m}$ and $\mathrm{Fe}(\mathrm{III})_{\text {dissolved }}$ was assumed to represent Fe present in small $(<0.2 \mu \mathrm{m})$, relatively stable complexes and denoted here as $\mathrm{Fe}(\mathrm{III})_{\text {colloid. }}$ Preliminary tests showed that addition of the $\mathrm{pH} 4$ buffer to samples did not affect this speciation. Immediately after the Fe measurements, $\mathrm{P}$ and Si were determined colorimetrically on separate subsamples of the $\mathrm{pH}$-buffered filtrates.

For the RDE, $4 \mathrm{~mL}$ of FeOx suspension $(\sim 100 \mathrm{mg}$ of FeOx $)$ was added to $500 \mathrm{~mL}$ of a solution containing $50 \mathrm{~g} \mathrm{~L}^{-1}$ sodium citrate $\left(\mathrm{C}_{6} \mathrm{H}_{5} \mathrm{Na}_{3} \mathrm{O}_{7}\right), 50 \mathrm{~g} \mathrm{~L}^{-1}$ sodium bicarbonate $\left(\mathrm{NaHCO}_{3}\right)$ and $20 \mathrm{~g} \mathrm{~L}^{-1}$ ascorbic acid $\left(\mathrm{C}_{6} \mathrm{H}_{8} \mathrm{O}_{6}\right)$ solution with a final $\mathrm{pH}$ of 7.8 and an $E_{h}$ of $\sim$ $-300 \mathrm{mV}$ (prepared using Ar-purged ultrapure $\mathrm{H}_{2} \mathrm{O}$ ). Ferric iron dissolved in this reducing solution may be a reasonable estimate for Fe(III) available for microbial dissimilatory Fe 
reduction (Hyacinthe et al., 2006). The suspensions were continuously stirred and purged with Ar to avoid introduction of $\mathrm{O}_{2}$ over the course of the experiment. At set time intervals, 6 $\mathrm{mL}$ samples were taken and filtered over $0.2 \mu \mathrm{m}$ Nylon filter membranes. Dissolved Fe(II) $\left(\mathrm{Fe}(\mathrm{II})_{\text {dissolved }}\right)$ was immediately determined in a subsample of the filtrate with the $1,10-$ phenanthroline (Sigma Aldrich) colorimetric method. Total $\mathrm{Fe}<0.2 \mu \mathrm{m}(\mathrm{Fe}<0.2 \mu \mathrm{m})$ was measured after addition of an aliquot of $100 \mathrm{~g} \mathrm{~L}^{-1}$ hydroxylamine- $\mathrm{HCl}$ (Merck) reducing agent and overnight reaction. The difference between $\mathrm{Fe}_{<0.2 \mu \mathrm{m}}$ and $\mathrm{Fe}(\mathrm{II})_{\text {dissolved }}$ was assumed to represent small complexes ( $\left.\mathrm{Fe}_{\text {colloid }}\right)$. In addition, soluble reactive $\mathrm{P}$ and $\mathrm{Si}$ were determined on separate subsamples using the molybdenum blue methods. Relative errors from duplicate experiments were generally $<5 \%$ for $\mathrm{Fe}$ and $\mathrm{P}$, and up to $10 \%$ for $\mathrm{Si}$.

\subsection{Equations for FeOx dissolution kinetics}

In order to facilitate the comparison of dissolution rates between experiments, the rates as function of reaction progress were obtained using the equation described in Postma (1993) and Larsen and Postma (2001):

$$
J=k m_{0} f\left(m / m_{0}\right) g(C)
$$

where $J$ represents the overall rate of dissolution $\left(\mathrm{mol} \mathrm{s}^{-1}\right), k$ represents the rate constant

$\left(\mathrm{s}^{-1}\right), m_{0}$ represents the initial amount of $\mathrm{FeOx}(\mathrm{mol})$ and $m$ represents the amount of undissolved $\mathrm{FeOx}(\mathrm{mol})$. In addition, $f\left(\mathrm{~m} / \mathrm{m}_{0}\right)$ is a function of changing $\mathrm{FeOx}$ characteristics during dissolution (particle size, morphology, site density), and $g(C)$ is a function of solution composition, accounting for kinetic effects of reactions at the FeOx surface. In concentrated solutions as used in the ADE and RDE, $g(C)$ can be considered constant and equation 1 reduces to: 


$$
J / m_{0}=k^{\prime}\left(m / m_{0}\right)^{\gamma}
$$

where $k^{\prime}=k g(C)$ and $\gamma$ represents the fitting parameter describing the changing particle properties during dissolution. Equation 2 can be integrated and rewritten as:

$$
m / m_{0}=\left[-k^{\prime}(1-\gamma) t+1\right]^{\frac{1}{1-\gamma}}
$$

Values of $k^{\prime}$ and $\gamma$ were obtained by non-linear least squares regression fitting of the experimentally determined $\mathrm{m} / \mathrm{m}_{0}$ versus $t$ data using the software package R (R.Core.Team, 2013).

\section{Results}

\subsection{Characterization of FeOx}

The $\mathrm{P} / \mathrm{Fe}$ and $\mathrm{Si} / \mathrm{Fe}$ ratios for the various $\mathrm{FeOx}$ are shown in Table 1 . The XRD spectra of all FeOx showed two broad peaks, centered around $\sim 40$ and $75^{\circ} 2 \theta$ that are characteristic for 2-line ferrihydrite (data not shown). The peak amplitudes were slightly lower for P9-cop FeOx compared to all other FeOx.

Iron K-edge EXAFS spectra showed subtle differences between 2L-Fh and P-cop/Si-cop FeOx at the highest oxyanion loading (Fig. 1A - C). The shoulder feature at $k=5.1 \AA^{-1}$, a characteristic feature of 2L-Fh that is not observed in the Fe K-edge EXAFS spectra of less ordered Fe(III) precipitates (Voegelin et al., 2010; van Genuchten et al., 2014), was slightly weaker in the P9-cop and Si9-cop FeOx samples than for pure FeOx. In addition, the second $(\mathrm{R}+\Delta \mathrm{R}=2.4 \AA)$ and third $(\mathrm{R}+\Delta \mathrm{R}=3.1 \AA)$ peak in the Fourier-transformed spectra (Fig. 1D F) that represent edge-sharing and corner-sharing Fe octahedra, respectively (Voegelin et al., 
2010; van Genuchten et al., 2014), were smaller for P9-cop FeOx and Si9-cop FeOx than for pure FeOx. This suggests decreased structural order or a lower degree of polymerization compared to pure $\mathrm{FeOx}$ (Voegelin et al., 2010). There were no significant differences in the Fe K-edge EXAFS spectra for pure FeOx and P-ads/Si-ads FeOx (data not shown).

The pair distribution functions (PDFs) obtained from HEXS showed an overall decrease in peak amplitude for $\mathrm{FeOx}$ with coprecipitated $\mathrm{P}$ or $\mathrm{Si}$ compared to pure $\mathrm{FeOx}$ (Fig. 2A). There were only very minor differences between the PDFs of fresh and aged pure FeOx. Subtracting the PDF of pure FeOx (here, the mean of the very similar spectra for fresh and aged 2L-Fh) from the PDFs for the P-cop FeOx and Si-cop FeOx further emphasizes the structural changes by coprecipitation of $\mathrm{P}$ and Si during FeOx formation (Fig. 2B). The P-cop and $\mathrm{Si}$-cop FeOx showed relatively high amplitudes (i.e. a positive $\Delta \mathrm{G}$ ) at $\sim 1.6$ and $\sim 3.2 \AA$, indicative of $\mathrm{P} / \mathrm{Si}-\mathrm{O}$ and $\mathrm{P} / \mathrm{Si}-\mathrm{Fe}$ bonds respectively (van Genuchten et al., 2014). Moreover, a relatively low amplitude for P-cop FeOx and Si-cop FeOx was observed at $~ 3.4$ $\AA$, the interatomic distance of corner-sharing $\mathrm{Fe}-\mathrm{Fe}$ bonds. Peak heights generally decreased in the order: pure $\mathrm{FeOx}>$ P4-cop FeOx $\approx$ Si4-cop FeOx O $>$ Si9-cop FeOx $>$ P9-cop FeOx. The maximum interatomic distance at which well-defined peaks are evident in the PDFs, which is a measure for nanoparticle dimensions (Chapman and Chupas, 2013), was $\sim 2 \mathrm{~nm}$ for all FeOx except P9-cop FeOx $(\sim 1.5 \mathrm{~nm})$.

\subsection{Sorption of phosphate and silicate by ferrihydrite}

Sorption of phosphate onto pure FeOx reached an asymptotic maximum of $\sim 2000 \mu \mathrm{mol}$ P per $\mathrm{g} \mathrm{FeOx}$ at $\mathrm{pH} 7$ (the $\mathrm{pH}$ used for synthesis of P-ads and Si-ads Fh for the ADE and $\mathrm{RDE}$ ). The high maximum concentration of adsorbed Si most likely was the result of Si polymerization at the FeOx surface at the high end of the Si sorption curve (Fig. S1B). Fitting a sorption curve only to data for $\mathrm{Si} / \mathrm{Fe}$ ratios at which $\mathrm{Si}$ polymerization was likely 
insignificant suggested a sorption capacity of $\sim 1000 \mu \mathrm{mol}$ Si per g FeOx. Further information on the results of the sorption experiments can be found in the Supplementary Information.

\subsection{Acidic and reductive FeOx dissolution}

The dissolution of (P- and Si-bearing) FeOx was assessed from the accumulation of $\mathrm{Fe}, \mathrm{P}$ and Si in solution (consisting of dissolved and colloidal species $<0.2 \mu \mathrm{m}$ ) (Fig. 3, 4). From the $\mathrm{Fe}(\mathrm{III})_{\text {dissolved }}$ and $\mathrm{Fe}(\mathrm{II})_{\text {dissolved }}$ values obtained from $\mathrm{ADE}$ and $\mathrm{RDE}$, respectively (see section 2.5), dissolution rates for each type of $\mathrm{FeOx}$ were calculated as described in section 2.6 and fitting parameters are shown in Table 2. The normalized rates $\left(\mathrm{J} / \mathrm{m}_{0}\right)$ are presented as a function of the remaining fraction of $\mathrm{FeOx}, \mathrm{m} / \mathrm{m}_{0}$ (Fig. 5). For all $\mathrm{FeOx}$, the dissolution rate decreased with progressing FeOx dissolution. While standard deviation of replicate measurements of any FeOx within a run was small (error bars in Fig. 3, 4), there were relatively large differences in 2L-Fh dissolution behavior between runs (Fig. 3, 4, 5; for explanation on the runs see section 2.5). P-cop FeOx and Si-cop FeOx showed enhanced dissolution rates compared to pure $\mathrm{FeOx}$ under both acidic and reductive conditions. These FeOx generally showed fastest dissolution rates at the highest oxyanion loading for both $\mathrm{ADE}$ and $\mathrm{RDE}$ (except for Si-cop FeOx in RDE). Consistent with the dissolution rate, the fraction of FeOx dissolved at the end of $\mathrm{ADE}$ and $\mathrm{RDE}$ was higher for P-cop and Si-cop FeOx compared to pure FeOx.

Adsorption of $\mathrm{P}$ and $\mathrm{Si}$ initially caused decreased $\mathrm{FeOx}$ dissolution rates under both acidic and reducing conditions (Fig. 3, 4). At the end of ADE and RDE, however, the fraction of dissolved $\mathrm{Fe}$ for $\mathrm{P}$-ads $\mathrm{FeOx}$ and $\mathrm{Si}$-ads $\mathrm{FeOx}$ was comparable to or higher than that for pure FeOx $(70-80 \%)$, with the exception of $\mathrm{P} 10$-ads FeOx in ADE experiments (50\%). That is, the highest loading with adsorbed $\mathrm{P}$ retarded acidic FeOx dissolution throughout the whole 
experiment, which was reflected by a relatively high $\gamma$ value for P10-ads FeOx in ADE (Table 2). In all other experiments with adsorbed $\mathrm{P}$ and $\mathrm{Si}$, the retardation was only effective at the beginning and was compensated towards the end of the experiment.

For pure $\mathrm{FeOx}$ during both $\mathrm{ADE}$ and $\mathrm{RDE}, \mathrm{Fe}_{\text {colloid }}$ shows a strong increase during the first few hours of the dissolution experiments, up to $\sim 60 \%$ of total $\mathrm{Fe}$, and a subsequent decrease to a fraction of $20-40 \%$ that is relatively stable for the remainder of each experiment (Fig. 3A, F; Fig. 4A, F). During acidic dissolution of FeOx, coprecipitated and adsorbed $\mathrm{P}$ suppresses the release of $\mathrm{Fe}_{\text {colloid }}$ (Fig. 3B - E). Such inhibition of $\mathrm{Fe}_{\text {colloid }}$ accumulation is also observed for adsorbed $\mathrm{Si}-$ be it to a lesser extent - but not coprecipitated Si under acidic conditions (Fig. 3G - J). During reductive dissolution, temporal trends in the relative contribution of $\mathrm{Fe}_{\text {colloid }}$ were less apparent, apart from a relatively fast accumulation for $\mathrm{P}$-cop $\mathrm{FeOx}$ compared to all other $\mathrm{FeOx}$.

Under acidic conditions, release of $\mathrm{P}$ and Si from the solid phase into solution lagged release of $\mathrm{Fe}(\mathrm{III})_{\text {dissolved }}$ (Fig. 3D-E, I-J). The lag time was greater for P-ads FeOx than P-cop FeOx. For adsorbed $\mathrm{P}$, the lag was most pronounced at higher $\mathrm{P}$ loading. The incongruent dissolution resulted in high initial Fe/P ratios in solution during the first hours (up to $10 \mathrm{~h}$, for P5-ads FeOx) that later declined to values more representative of the bulk FeOx composition. The Si-bearing FeOx showed no such lag effect during acidic dissolution; the release of $\mathrm{Si}$ into solution exceeded that of (total) Fe, particularly during the early stages of $\mathrm{FeOx}$ dissolution. As a result, the Fe/Si ratio in solution was initially low and gradually increased over the course of Si-cop FeOx dissolution. No such lag effect was observed for RDE, during which $\mathrm{P}$ and Si accumulation in solution was rapid and initially exceeded the rate of $\mathrm{Fe}$ accumulation (Fig. 4). 


\section{Discussion}

\subsection{The impact of oxyanion coprecipitation on FeOx structure}

Two main pathways of $\mathrm{FeOx}$ precipitation are $\mathrm{Fe}(\mathrm{II})$ oxidation and $\mathrm{Fe}(\mathrm{III})$ hydrolysis. Previous work has shown that the presence of even small amounts of oxyanions such as phosphate and silicate can alter the structure of $\mathrm{FeOx}$ formed during $\mathrm{Fe}(\mathrm{II})$ oxidation. This arises from the occupation of binding sites by the oxyanions during FeOx nucleation, which hinders $\mathrm{FeO}_{6}$ polymerization and $\mathrm{FeOx}$ crystallization (Voegelin et al., 2010; van Genuchten et al., 2014; Senn et al., 2015). In particular, the Fe(II)-catalyzed crystallization of poorly ordered FeOx is inhibited (Boland et al., 2014) and as a result, poorly ordered FeOx persists in the presence of $\mathrm{P}$ and $\mathrm{Si}$ over experimental durations of $2-5 \mathrm{~h}$ during $\mathrm{Fe}(\mathrm{II})$ oxidation. This effect of $\mathrm{P}$ and Si coprecipitation has been observed at initial $\mathrm{P} / \mathrm{Fe}$ ratios down to 0.02 (Voegelin et al., 2010). Sorption of oxyanions such as phosphate and silicate onto FeOx surface sites can effectively stabilize poorly ordered FeOx and inhibit their transformation to more crystalline phases over long timescales of at least days to weeks (Cornell et al., 1987; Paige et al., 1997b; Senn et al., 2017). As such, the transformation kinetics of FeOx depend critically on the chemical conditions under which they exist.

In contrast to $\mathrm{Fe}(\mathrm{II})$ oxidation experiments, the presence of oxyanions is shown to have more subtle effect on the structure of FeOx formed by $\mathrm{Fe}(\mathrm{III})$ hydrolysis from concentrated solution $(\mathrm{Fe}(\mathrm{III})>100 \mathrm{mM})$. This is partly because $\mathrm{Fe}(\mathrm{II})$-catalyzed crystallization processes do not play a role under the latter experimental conditions. When FeOx forms by the hydrolysis of $\mathrm{Fe}(\mathrm{III})$ solutions, coprecipitated oxyanions affect $\mathrm{FeOx}$ formation by occupation of crystal growth sites during Fe(III) polymerization. This "poisoning” of FeOx surface sites interferes with Fe-Fe bond formation and decreases the structural coherency of already poorly ordered $\mathrm{FeOx}(2 \mathrm{~L}-\mathrm{Fh})$ formed by $\mathrm{Fe}(\mathrm{III})$ hydrolysis at circumneutral $\mathrm{pH}$. This effect is reflected in Fourier-transformed Fe EXAFS data of FeOx with coprecipitated $\mathrm{P}$ or $\mathrm{Si}$ 
by decreased magnitude peaks for Fe-Fe interatomic pairs, most notably corner-sharing bonds, and a strong disruption of Fe-Fe bond formation at oxyanion/Fe ratios $>0.2$

(Waychunas et al., 1993; Rose et al., 1996; Pokrovski et al., 2003).

The $\mathrm{P} / \mathrm{Fe}$ and $\mathrm{Si} / \mathrm{Fe}$ ratios used in this study were relevant for natural systems (up to 0.1 ) and generally lower than those applied in the aforementioned studies. Consequently, we observed more subtle effects of $\mathrm{P}$ and Si coprecipitation on FeOx structure. Specifically, our results show a decrease in the magnitude peak arising from corner-sharing Fe-Fe bonds in both the Fe EXAFS $(\sim 3.1 \AA)$ and HEXS $(\sim 3.4 \AA)$ data (Fig. 1D - F, Fig. 2). Additionally, the HEXS results showed increased magnitude peaks for P-cop FeOx and Si-cop FeOx compared to $2 \mathrm{~L}-\mathrm{Fh}$ at $\sim 1.6 \AA$ and $~ 3.2 \AA$, arising from $\mathrm{Si} / \mathrm{P}-\mathrm{O}$ and $\mathrm{Si} / \mathrm{P}-\mathrm{Fe}$ bonds, respectively (van Genuchten et al., 2014). The HEXS data also showed that the impact of P or Si coprecipitation increased with oxyanion loading, and that at similar loading the impact of $\mathrm{P}$ coprecipitation exceeded that of Si coprecipitation (as evident at the three highlighted interatomic distances 1.6, 3.2 and 3.4 $\AA$ in the PDFs in Fig. 3). In addition, at the highest $\mathrm{P}$ loading $(\mathrm{Fe} / \mathrm{P}=0.1)$ the particle size as reflected in the coherent scattering domain of the PDF decreased from $\sim 0.2$ to $0.15 \mathrm{~nm}$ (Fig. 2A).

Overall, the EXAFS and HEXS results show that the presence of $\mathrm{P}$ and Si during FeOx formation by base hydrolysis of a concentrated Fe(III) solution has a minor impact on the structure of the already poorly ordered $\mathrm{FeOx}$ that forms under such experimental conditions. Based on structural alteration as probes by EXAFS and HEXS, we would therefore expect a minor impact of $\mathrm{P}$ and Si coprecipitation, notwithstanding the impact that interaction with oxyanions can have on the macroscopic properties of FeOx such as aggregation (e.g. Cornell et al., 1987; Paige et al., 1997b; van Genuchten et al., 2014). 


\subsection{FeOx dissolution kinetics and the impact of interaction with $P, S i$}

\subsubsection{Aging effects on FeOx reactivity}

The minor differences in the Fe EXAFS and HEXS spectra of fresh and aged 2L-Fh (Fig. $1,2)$ suggest that structural alteration of the $2 \mathrm{~L}-\mathrm{Fh}$ during four weeks of aging was insignificant. Nonetheless, we observed differences in 2L-Fh dissolution between repeated runs that were two weeks apart for both $\mathrm{ADE}$ and RDE (Fig. 3A, F, 4A, F). Variations in pure $\mathrm{FeOx}$ dissolution rates do not correlate with the age of the suspensions: dissolution of pure $\mathrm{FeOx}$ was slower during run 2 of the ADE, while it was faster during run 2 of the RDE. The small standard deviations for duplicates of each specific FeOx within an experimental run argue against major random variation in dissolution behavior. Furthermore, the different FeOx used in this study (no, coprecipitated or adsorbed phosphate and silicate) were likely differently affected by mineral aging (Cornell et al., 1987; Senn et al., 2017). Considering these uncertainties, we use the average pure $\mathrm{FeOx}$ dissolution rate to assess the impact of adsorption or coprecipitation of $\mathrm{P}$ and $\mathrm{Si}$ on $\mathrm{FeOx}$ dissolution kinetics.

\subsubsection{Kinetics of acidic versus reductive dissolution}

The dissolution rate was about an order of magnitude higher in the RDE compared to ADE (Figure 5). This can be attributed to the formation of easily detachable complexes of reduced Fe(II) and ligands at the particle surface during RDE (Zinder et al., 1986) that results in more rapid mineral dissolution than occurs due to proton-induced bond weakening during ADE. All components of the citrate-bicarbonate-ascorbic acid solution used for RDE can adsorb onto the surface of FeOx particles and thus contribute to surface complex detachment (Kallay and Matijevic, 1985; van Geen et al., 1994; Deng, 1997; Nemade et al., 2007). The concentration of ligands was sufficient to saturate all FeOx surface sites, which also explains 
the rapid release of $\mathrm{P}$ and $\mathrm{Si}$ into solution during the $\mathrm{RDE}$, and the apparent lack of readsorption (Fig. 3, 4).

\subsubsection{Contrasting effects of oxyanion coprecipitation and adsorption on $\mathrm{FeOx}$ reactivity}

Coprecipitation of $\mathrm{P}$ and $\mathrm{Si}$ at the low initial oxyanion/Fe ratios in this study $(0.04-0.1)$ had a relatively minor impact on mineral structure, with subtle decreases in structural coherency compared to 2L-Fh as probed by EXAFS and HEXS (Fig. 1, 2). Yet, the dissolution rates of $\mathrm{P}$-cop $\mathrm{FeOx}$ and $\mathrm{Si}$-cop FeOx during the $\mathrm{ADE}$ and $\mathrm{RDE}$ increased relative to that of pure FeOx (Fig. 5). The dissolution rate increased with $\mathrm{P}$ or Si loading, with highest rates observed for P9-cop FeOx, which consisted of smaller crystallites $(\sim 1.5 \mathrm{~nm})$ compared to all other $\mathrm{FeOx}(\sim 2 \mathrm{~nm})$. Considering that $\mathrm{P}$ and $\mathrm{Si}$ coprecipitation at the chosen loadings resulted in only minor structural $\mathrm{FeOx}$ alteration, our results indicate that $\mathrm{FeOx}$ formation in the presence of $\mathrm{P}$ or $\mathrm{Si}$ affected the macroscopic properties of $\mathrm{FeOx}$ and thereby $\mathrm{FeOx}$ dissolution. For instance, occupation of $\mathrm{FeO}_{6}$ surface sites by phosphate or silicate during Fe(III) particle formation can inhibit particle aggregation (Kaegi et al., 2010). This would not be detected by the employed X-ray techniques that are sensitive to short-range structure, but can impact overall reactivity.

While oxyanion coprecipitation increased $\mathrm{FeOx}$ reactivity, adsorption of $\mathrm{P}$ and Si resulted in decreased $\mathrm{FeOx}$ dissolution rates. This is in line with earlier work that showed adsorption of oxyanions such as phosphate and $\mathrm{AsO}_{4}$ stabilized $\mathrm{FeOx}$ mineral surfaces and decreased FeOx reactivity (Biber et al., 1994; Jones et al., 2009; Majzlan, 2011). Assuming that a molar $\mathrm{P} / \mathrm{Fe}$ ratio $\left(\Gamma_{\mathrm{PO} 4}\right)$ of $\sim 0.2$ corresponds to saturation of reactive surface sites for pure $2 \mathrm{~L}-\mathrm{Fh}$ (Dzombak and Morel, 1990), only up to about half of the available reactive surface sites became occupied during our experiments. In addition, Si was adsorbed onto $\mathrm{FeOx}$ at lower loadings (oxyanion/Fe ratios) than $\mathrm{P}$ but $\mathrm{Si}$-ads $\mathrm{FeOx}$ showed lower dissolution rates than $\mathrm{P}$ - 
ads FeOx (Fig. 5), further suggesting that occupation of surface sites is not the only factor determining the dissolution behavior of $\mathrm{FeOx}$ with adsorbed $\mathrm{P}$ or Si. We therefore propose that the decreased reactivity of $\mathrm{FeOx}$ with adsorbed $\mathrm{P}$ or $\mathrm{Si}$ at low loadings may be the result of occupation of reactive surface sites as well as particle aggregation, promoted by sorption of $\mathrm{P}$ and Si onto pre-existing FeOx surfaces (Cornell et al., 1987; Paige et al., 1997b). As such, altered macroscopic mineral properties may contribute to the opposite effects of coprecipitation and adsorption on FeOx reactivity.

All dissolution experiments showed a transient increase in $\mathrm{Fe}_{\text {colloid }}\left(=\mathrm{Fe}<0.2 \mu \mathrm{m}-\mathrm{Fe}_{\text {dissolved }}\right)$, suggesting the presence of nanoparticles $<0.2 \mu \mathrm{m}$ in the first $1-10 \mathrm{~h}$ of the experiments. The onset of colloid release occurs after dissolution of $15-20 \%$ of FeOx in all experiments, which could signify a common change in dissolution mechanism from surface dissolution to detachment of nanoparticles from the original FeOx solid phase. During acidic dissolution, oxyanion coprecipitation as well as adsorption limits the release of colloidal Fe into solution, in particular for P-bearing FeOx (Fig 3A - E). However, the normalized dissolution rate of Pcop FeOx exceeds that of P-ads FeOx (Fig. 5A). This suggests that colloidal Fe released from P-cop FeOx is relatively unstable and dissolves rapidly, while release of colloidal Fe from Pads FeOx is limited; overall the dissolution of $\mathrm{P}$-ads FeOx proceeds more slowly.

\subsubsection{Timing and stoichiometry of oxyanion release during $\mathrm{FeOx}$ dissolution}

Besides differences in $\mathrm{FeOx}$ dissolution behavior as assessed from dissolved $\mathrm{Fe}$ data, we observed differences in the release of $\mathrm{Fe}$ and $\mathrm{P}$ or Si during FeOx dissolution. During RDE, $\mathrm{P}$ and $\mathrm{Si}$ were both rapidly released from the $\mathrm{FeOx}$ surface from all $\mathrm{FeOx}$ (Fig. 4), likely because of the aforementioned competition of added ligands with P and Si for surface sites (section 4.2.2). By contrast, the temporal release patterns during the ADE differed markedly for $\mathrm{P}$ and $\mathrm{Si}$. Release of $\mathrm{Si}$ was rapid for $\mathrm{Si}$-ads $\mathrm{FeOx}$ as well as $\mathrm{Si}-\mathrm{cop} \mathrm{FeOx}$ and initially 
exceeded Fe accumulation in solution: $25-35 \%$ of total Si was in solution at the first sampling point, compared to $<10 \%$ of $\mathrm{Fe}(\mathrm{III})_{<0.2 \mu \mathrm{m}}(\mathrm{Fig}$. $3 \mathrm{G}-\mathrm{J}$ ). This suggests that $\mathrm{Si}$ release was initially related to desorption rather than $\mathrm{FeOx}$ dissolution. The Si binding capacity of $\mathrm{FeOx}$ decreases at $\mathrm{pH}<9$ because $\mathrm{Si}$ adsorption results in a net release of $\mathrm{H}^{+}$ (Davis et al., 2002; Hiemstra et al., 2007). After the initial phase characterized by Si desorption, release of $\mathrm{Si}$ was more rapid for $\mathrm{Si}$-cop FeOx than Si-ads Fh (Fig. 3), in line with the difference in FeOx dissolution rates (Fig. 5).

Trends in the stoichiometry of $\mathrm{Fe}$ and $\mathrm{P}$ release during acidic dissolution of $\mathrm{P}$-bearing FeOx were very different to those observed during acidic dissolution of Si-bearing FeOx. For both $\mathrm{P}$-cop FeOx and P-ads FeOx, P release was limited during the initial stages of $\mathrm{FeOx}$ dissolution, resulting in high $\mathrm{Fe}(\mathrm{III})_{\text {dissolved }} / \mathrm{P}$ ratios (Fig. 3). We attribute the initial incongruent dissolution to readsorption of $\mathrm{P}$ onto remaining FeOx surface sites at $\mathrm{pH} 2$ of the $\mathrm{ADE}$, as the $\mathrm{P}$ sorption capacity of $\mathrm{FeOx}$ remains high at this $\mathrm{pH}$ (Antelo et al., 2005; Antelo et al., 2010). This readsorption may act to stabilize the surface of P-cop during dissolution and thus modulate its dissolution rate, but such an effect cannot be extracted from the available data.

The release of P into solution commenced when $15-20 \%$ of FeOx was dissolved. The calculated solid-phase $\mathrm{P} / \mathrm{Fe}$ ratios $(0.06-0.12)$ at this point were still below the maximum $\mathrm{P}$ loading of 2L-Fh of $\sim 0.2$ as was found previously (Dzombak and Morel, 1990) and confirmed by our $\mathrm{P}$ sorption data $(\mathrm{P} / \mathrm{Fe} \approx 0.22$ at $\mathrm{pH} 6)$. Therefore, depletion of accessible binding sites seems an unlikely explanation for the onset of $\mathrm{P}$ accumulation in solution. The timing of $\mathrm{P}$ release from the solid phase coincides with an observed increase in the $\mathrm{Fe}_{\text {colloid }}$ fraction. The aforementioned change in $\mathrm{FeOx}$ dissolution behavior from surface dissolution to release of Fe nanoparticles into solution may then have also affected P release. Soluble reactive $\mathrm{P}$ (SRP) as measured by the molybdenum-blue method is determined in an acidic 
$(\mathrm{pH}<1)$ medium containing dilute sulfuric acid that could rapidly dissolve P-bearing Fe colloids. As a result, the pool of soluble reactive P measured by this method could include dissolved $\mathrm{P}$ as well as $\mathrm{P}$ associated with these colloids.

\section{Conclusions and implications}

Interactions between $\mathrm{FeOx}$ and phosphate or silicate affect the structure and stability of the resulting oxyanion-bearing FeOx. The nature of the resulting effects depends strongly on whether the interaction occurs during or subsequent to $\mathrm{FeOx}$ formation. Coprecipitation of phosphate or silicate during $\mathrm{FeOx}$ formation decreases the degree of structural order and may inhibit particle aggregation, thereby enhancing FeOx dissolution rates under acidic and reducing conditions. Conversely, adsorption stabilizes the mineral surface and may enhance particle aggregation, leading to decreased dissolution rates. These effects are apparent even during coprecipitation with oxyanion/Fe ratios as low as $0.04 \mathrm{~mol} \mathrm{~mol}^{-1}$. At these low $\mathrm{P}$ and Si loadings, Fe K-edge EXAFS and HEXS data show only minor changes to the structural properties of the $\mathrm{FeOx}$, suggesting that alteration of macroscopic mineral properties (i.e. aggregation) plays a prominent role. The dissolution behavior of $\mathrm{FeOx}$ and the fate of associated oxyanions vary on timescales (days, weeks) that are relevant for dynamic natural systems. As such, increased pore water concentrations of oxyanions such as phosphate and silicate - as caused, for instance, by eutrophication - may enhance oxyanion coprecipitation, decrease mineral stability and eventually suppress the nutrient retention capacity of sediments with strong temporal and vertical redox gradients. This feedback in the eutrophication process of aquatic systems, which is so far unrecognized, should be further explored in light of the human-induced increase of nutrient delivery to aquatic systems and expansion of coastal areas with oxygen-depleted bottom waters. 


\section{Acknowledgements}

This work was funded by a grant from the Netherlands Organisation for Scientific Research, NWO Veni grant 863.14.014 to P. Kraal. Case M. van Genuchten acknowledges NWO Veni grant 14400. The work was further supported by a NWO DUBBLE grant 195.068.1039 for ESRF beamline BM26A. We gratefully thank the technical support and advice of Dipanjan Banerjee at the DUBBLE beamline during Fe K-edge EXAFS data collection. Simon Müller kindly assisted with data collection at ESRF. We thank the reviewer for valuable feedback.

\section{References}

Antelo, J., Avena, M., Fiol, S., López, R., Arce, F., 2005. Effects of pH and ionic strength on the adsorption of phosphate and arsenate at the goethite-water interface. J. Colloid Interface Sci. 285 (2), 476-486.

Antelo, J., Fiol, S., Pérez, C., Mariño, S., Arce, F., Gondar, D., López, R., 2010. Analysis of phosphate adsorption onto ferrihydrite using the CD-MUSIC model. J. Colloid Interface Sci. 347 (1), 112-119.

APHA, 2005. Standard methods for the examination of water and wastewater. American Public Health Association - American Water Works Association - Water Environment Federation.

Biber, M.V., dos Santos Afonso, M., Stumm, W., 1994. The coordination chemistry of weathering: IV. Inhibition of the dissolution of oxide minerals. Geochim. Cosmochim. Acta 58 (9), 1999-2010.

Boland, D.D., Collins, R.N., Miller, C.J., Glover, C.J., Waite, T.D., 2014. Effect of solution and solid-phase conditions on the Fe(II)-accelerated transformation of ferrihydrite to lepidocrocite and goethite. Environ. Sci. Technol. 48 (10), 5477-5485.

Borch, T., Masue, Y., Kukkadapu, R.K., Fendorf, S., 2007. Phosphate Imposed Limitations on Biological Reduction and Alteration of Ferrihydrite. Environ. Sci. Technol. 41 (1), 166-172.

Borsboom, M., Bras, W., Cerjak, I., Detollenaere, D., van Loon, D.G., Goedtkind, P., Konijnenburg, M., Lassing, P., Levine, Y.K., Munneke, B., Oversluizen, M., van Tol, R., Vlieg, E., 1998. The Dutch-Belgian beamline at the ESRF. J. Synchrotron Radiat. $5,518-520$.

Buffle, J., De Vitre, R.R., Perret, D., Leppard, G.G., 1989. Physico-chemical characteristics of a colloidal iron phosphate species formed at the oxic-anoxic interface of a eutrophic lake. Geochim. Cosmochim. Acta 53 (2), 399-408.

Chapman, K.W., Chupas, P.J., 2013. Pair distribution function analysis of high-energy X-ray scattering data. In: Rodriguez, J.A., Hanson, J.C., Chupas, P.J. (Eds.), In-situ Characterization of Heterogeneous Catalysts. John Wiley and Sons, Inc. 
Chupas, P.J., Qiu, X., Hanson, J.C., Lee, P.L., Grey, C.P., Billinge, S.J.L., 2003. Rapidacquisition pair distribution function (RA-PDF) analysis. J. Appl. Crystallogr. 36 (6), 1342-1347.

Cornell, R.M., Giovanoli, R., Schindler, P.W., 1987. Effect of silicate species on the transformation of ferrihydrite into goethite and hematite in alkaline media. Clays \& Clay Minerals 35 (1), 21-28.

Davis, C.C., Chen, H.-W., Edwards, M., 2002. Modeling Silica Sorption to Iron Hydroxide. Environ. Sci. Technol. 36 (4), 582-587.

Deng, Y., 1997. Effect of pH on the Reductive Dissolution Rates of Iron(III) Hydroxide by Ascorbate. Langmuir 13 (6), 1835-1839.

Dzombak, D.A., Morel, F.M.M., 1990. Surface complexation modeling: Hydrous ferric oxide. Wiley, New York, 416 pp.

Hammersley, A.P., Svensson, S.O., Hanfland, M., Fitch, A.N., Hausermann, D., 1996. Twodimensional detector software: From real detector to idealised image or two-theta scan. High Pressure Research 14 (4-6), 235-248.

Hiemstra, T., 2013. Surface and mineral structure of ferrihydrite. Geochim. Cosmochim. Acta $105(0), 316-325$.

Hiemstra, T., Barnett, M.O., van Riemsdijk, W.H., 2007. Interaction of silicic acid with goethite. J. Colloid Interface Sci. 310 (1), 8-17.

Hyacinthe, C., Bonneville, S., Van Cappellen, P., 2006. Reactive iron(III) in sediments: Chemical versus microbial extractions. Geochim. Cosmochim. Acta 70 (16), 41664180.

Jambor, J.L., Dutrizac, J.E., 1998. Occurrence and Constitution of Natural and Synthetic Ferrihydrite, a Widespread Iron Oxyhydroxide. Chemical Reviews 98 (7), 2549-2586.

Jones, A.M., Collins, R.N., Rose, J., Waite, T.D., 2009. The effect of silica and natural organic matter on the $\mathrm{Fe}$ (II)-catalysed transformation and reactivity of $\mathrm{Fe}$ (III) minerals. Geochim. Cosmochim. Acta 73 (15), 4409-4422.

Kaegi, R., Voegelin, A., Folini, D., Hug, S.J., 2010. Effect of phosphate, silicate, and Ca on the morphology, structure and elemental composition of Fe(III)-precipitates formed in aerated Fe(II) and As(III) containing water. Geochim. Cosmochim. Acta 74 (20), 5798-5816.

Kallay, N., Matijevic, E., 1985. Adsorption at solid/solution interfaces. 1. Interpretation of surface complexation of oxalic and citric acids with hematite. Langmuir 1 (2), 195201.

Kelly, S.D., Hesterberg, D., Ravel, B., 2008. Analysis of soils and minerals using X-ray absorption spectroscopy. In: Ulery, A.L., Drees, L.R. (Eds.), Methods of Soil Analysis Part 5-Mineralogical Methods. Soil Science Society of America, Madison, Wisconsin.

Kraal, P., Dijkstra, N., Behrends, T., Slomp, C.P., 2017. Phosphorus burial in sediments of the sulfidic deep Black Sea: key roles for adsorption by calcium carbonate and apatite authigenesis. Geochim. Cosmochim. Acta 204, 140-158.

Kukkadapu, R.K., Zachara, J.M., Fredrickson, J.K., Kennedy, D.W., 2004. Biotransformation of two-line silica-ferrihydrite by a dissimilatory Fe(III)-reducing bacterium: formation of carbonate green rust in the presence of phosphate1. Geochim. Cosmochim. Acta 68 (13), 2799-2814.

Larsen, O., Postma, D., 2001. Kinetics of reductive bulk dissolution of lepidocrocite, ferrihydrite, and goethite. Geochim. Cosmochim. Acta 65 (9), 1367-1379.

Majzlan, J., 2011. Thermodynamic stabilization of hydrous ferric oxide by adsorption of phosphate and arsenate. Environ. Sci. Technol. 45 (11), 4726-4732. 
Michel, F.M., Ehm, L., Antao, S.M., Lee, P.L., Chupas, P.J., Liu, G., Strongin, D.R., Schoonen, M.A.A., Phillips, B.L., Parise, J.B., 2007. The structure of ferrihydrite, a nanocrystalline material. Science 316 (5832), 1726-1729.

Mullin, J.B., Riley, J.P., 1955. The colorimetric determination of silicate with special reference to sea and natural waters. Anal. Chim. Acta 12, 162-176.

Nemade, P., Kadam, A.M., Oza, G., Dutta, S.M., Shankar, U.S., 2007. Effects of anions on arsenic adsorption with iron hydroxide - A review. Indian J. Environ. Prot. 27 (12), 1057-1064.

Nikitenko, S., Beale, A.M., van der Eerden, A.M.J., Jacques, S.D.M., Leynaud, O., O'Brien, M.G., Detollenaere, D., Kaptein, R., Weckhuysen, B.M., Bras, W., 2008.

Implementation of a combined SAXS/WAXS/QEXAFS set-up for time-resolved in situ experiments. J. Synchrotron Radiat. 15 (6), 632-640.

Norkko, J., Reed, D.C., Timmermann, K., Norkko, A., Gustafsson, B.G., Bonsdorff, E., Slomp, C.P., Carstensen, J., Conley, D.J., 2012. A welcome can of worms? Hypoxia mitigation by an invasive species. Glob. Change Biol. 18 (2), 422-434.

Paige, C.R., Snodgrass, W.J., Nicholson, R.V., Scharer, J.M., 1997a. An arsenate effect on ferrihydrite dissolution kinetics under acidic oxic conditions. Water Res. 31 (9), 23702382.

Paige, C.R., Snodgrass, W.J., Nicholson, R.V., Scharer, J.M., He, Q.H., 1997b. The effect of phosphate on the transformation of ferrihydrite into crystalline products in alkaline media. Water, Air, \& Soil Pollution 97 (3), 397-412.

Pham, A.N., Rose, A.L., Feitz, A.J., Waite, T.D., 2006. Kinetics of Fe(III) precipitation in aqueous solutions at $\mathrm{pH}$ 6.0-9.5 and $25^{\circ} \mathrm{C}$. Geochim. Cosmochim. Acta 70 (3), 640650.

Pokrovski, G.S., Schott, J., Farges, F., Hazemann, J.-L., 2003. Iron (III)-silica interactions in aqueous solution: insights from X-ray absorption fine structure spectroscopy. Geochim. Cosmochim. Acta 67 (19), 3559-3573.

Postma, D., 1993. The reactivity of iron oxides in sediments: A kinetic approach. Geochim. Cosmochim. Acta 57 (21-22), 5027-5034.

R.Core.Team, 2013. R: A language and environment for statistical computing, Vienna, Austria.

Ravel, B., Newville, M., 2005. Athena, Artemis, Hephaestus: data analysis for X-ray absorption spectroscopy using IFEFFIT. J. Synchrotron Radiat. 12, 537-541.

Rose, J., Manceau, A., Bottero, J.-Y., Masion, A., Garcia, F., 1996. Nucleation and Growth Mechanisms of Fe Oxyhydroxide in the Presence of PO4 Ions. 1. Fe K-Edge EXAFS Study. Langmuir 12 (26), 6701-6707.

Rose, S., Ghazi, A.M., 1998. Experimental study of the stability of metals associated with iron oxyhydroxides precipitated in acid mine drainage. Environ. Geol. 36 (3), 364370.

Schoepfer, V.A., Burton, E.D., Johnston, S.G., Kraal, P., 2017. Phosphate-imposed constraints on schwertmannite stability under reducing conditions. Environ. Sci. Technol. 51 (17), 9739-9746.

Schwertmann, U., Cornell, S., 1991. Iron oxides in the laboratory: Preparation and characterization. Wiley, $188 \mathrm{pp}$.

Senn, A.-C., Kaegi, R., Hug, S.J., Hering, J.G., Mangold, S., Voegelin, A., 2015. Composition and structure of $\mathrm{Fe}(\mathrm{III})$-precipitates formed by $\mathrm{Fe}(\mathrm{II})$ oxidation in water at near-neutral $\mathrm{pH}$ : Interdependent effects of phosphate, silicate and $\mathrm{Ca}$. Geochim. Cosmochim. Acta 162 (0), 220-246. 
Senn, A.-C., Kaegi, R., Hug, S.J., Hering, J.G., Mangold, S., Voegelin, A., 2017. Effect of aging on the structure and phosphate retention of $\mathrm{Fe}(\mathrm{III})$-precipitates formed by $\mathrm{Fe}(\mathrm{II})$ oxidation in water. Geochim. Cosmochim. Acta 202, 341-360.

Strickland, J.D., Parsons, T.R., 1972. A practical handbook of seawater analysis, Bulletin 167. Fish. Res. Board Canada.

Stumm, W., 1997. Reactivity at the mineral-water interface: dissolution and inhibition. Colloids and Surfaces A: Physicochemical and Engineering Aspects 120 (1), 143-166.

van Geen, A., Robertson, A.P., Leckie, J.O., 1994. Complexation of carbonate species at the goethite surface: Implications for adsorption of metal ions in natural waters. Geochim. Cosmochim. Acta 58 (9), 2073-2086.

van Genuchten, C.M., Peña, J., 2016. Antimonate and arsenate speciation on reactive soil minerals studied by differential pair distribution function analysis. Chem. Geol. 429, $1-9$.

van Genuchten, C.M., Peña, J., Amrose, S.E., Gadgil, A.J., 2014. Structure of Fe(III) precipitates generated by the electrolytic dissolution of $\mathrm{Fe}(0)$ in the presence of groundwater ions. Geochim. Cosmochim. Acta 127, 285-304.

Voegelin, A., Kaegi, R., Frommer, J., Vantelon, D., Hug, S.J., 2010. Effect of phosphate, silicate, and $\mathrm{Ca}$ on $\mathrm{Fe}(\mathrm{III})$-precipitates formed in aerated $\mathrm{Fe}(\mathrm{II})$ - and $\mathrm{As}$ (III)containing water studied by X-ray absorption spectroscopy. Geochim. Cosmochim. Acta 74 (1), 164-186.

Voegelin, A., Senn, A.-C., Kaegi, R., Hug, S.J., Mangold, S., 2013. Dynamic Fe-precipitate formation induced by $\mathrm{Fe}(\mathrm{II})$ oxidation in aerated phosphate-containing water. Geochim. Cosmochim. Acta 117 (0), 216-231.

Waychunas, G.A., Rea, B.A., Fuller, C.C., Davis, J.A., 1993. Surface chemistry of ferrihydrite: Part 1. EXAFS studies of the geometry of coprecipitated and adsorbed arsenate. Geochim. Cosmochim. Acta 57 (10), 2251-2269.

Webster, J.G., Swedlund, P.J., Webster, K.S., 1998. Trace Metal Adsorption onto an Acid Mine Drainage Iron(III) Oxy Hydroxy Sulfate. Environ. Sci. Technol. 32 (10), 13611368.

Zinder, B., Furrer, G., Stumm, W., 1986. The coordination chemistry of weathering: II. Dissolution of Fe(III) oxides. Geochim. Cosmochim. Acta 50 (9), 1861-1869. 


\section{Figure captions}

Figure 1. Iron K-edge EXAFS spectra $(\mathrm{A}-\mathrm{C})$ and Fourier-transformed iron K-edge EXAFS spectra $(\mathrm{D}-\mathrm{F})$ of the various synthesized hydrous ferric oxides. The plots for FeOx with coprecipitated $\mathrm{P}$ or Si show the spectrum of fresh pure $\mathrm{FeOx}$ as gray dashed line for reference.

Figure 2. (A) Atomic pair distribution functions (PDF) of synthesized FeOx determined by high energy X-ray scattering, HEXS. The results are plotted out to $6 \AA$, focusing on local structure (i.e. the first few coordination spheres). The inset in panel A shows the full-range PDFs, where arrows indicate the maximum interatomic distance at which well-defined peaks are evident in the PDF for P9-cop FeOx $(\sim 1.5 \mathrm{~nm})$ and all other FeOx $(\sim 2 \mathrm{~nm})$. (B) PDFs for FeOx with coprecipitated $\mathrm{P}$ or Si plotted as difference between the FeOx spectrum and that of the mean of the two 2L-Fh spectra. Vertical grey bars indicate key atomic distances where the amplitude in the PDF is different for the P-and $\mathrm{Si}$-cop FeOx compared to pure FeOx: $\sim 1.6 \AA$ $(\mathrm{Si} / \mathrm{P}-\mathrm{O}), \sim 3.2 \AA(\mathrm{Si} / \mathrm{P}-\mathrm{Fe})$ and $3.4 \AA(\mathrm{Fe}-\mathrm{Fe})$.

Figure 3. Kinetics of total Fe $<0.2 \mu \mathrm{m}$ (white), dissolved Fe (black), colloidal Fe (gray) and soluble reactive $\mathrm{P}$ and $\mathrm{Si}(\mathrm{red})$ accumulation in the acidic dissolution experiment $\left(0.01 \mathrm{~mol} \mathrm{\textrm {L } ^ { - }}\right.$ $\left.{ }^{1} \mathrm{HCl}, \mathrm{pH} 2\right)$ for the different types of $\mathrm{FeOx}$. Orange lines show solution $\mathrm{Fe}^{3+}$ dissolved $(\mathrm{P}$ or $\mathrm{Si})$ ratio. Pure FeOx 1 was part of ADE series 1, which included 2L-Fh and all P-bearing Fe(III) phases in duplicate. Pure FeOx 2 was part of ADE series 2 with all Si-bearing FeOx. All symbols represent the mean and error bars represent the standard deviation $(n=2)$. Note the logarithmic $\mathrm{x}$ axis. 
Figure 4. Kinetics of total $\mathrm{Fe}<0.2 \mu \mathrm{m}$ (white), dissolved Fe (black), colloidal Fe (gray) and soluble reactive $\mathrm{P}$ and $\mathrm{Si}$ (red) accumulation in the reductive dissolution experiment $\left(20 \mathrm{~g} \mathrm{~L}^{-1}\right.$ ascorbic acid, $\mathrm{pH}$ 7.8) for the different types of FeOx. Orange lines show solution $\mathrm{Fe}^{3+}{ }_{\text {dissolved }} /(\mathrm{P}$ or $\mathrm{Si}$ ) ratio. Pure $\mathrm{FeOx} 1$ was part of RDE series 1 , which included $2 \mathrm{~L}-\mathrm{Fh}$ and all P-bearing Fe(III) phases in duplicate. Pure FeOx 2 was part of RDE series 2 with all Sibearing FeOx. All symbols represent the mean and error bars represent the standard deviation $(n=2)$. Note the logarithmic $\mathrm{x}$ axis.

Figure 5. Normalized dissolution rate $\left(\mathrm{J} / \mathrm{m}_{0}\right.$ in $\left.\mathrm{s}^{-1}\right)$ plotted against fraction of remaining $\mathrm{FeOx}$ $\left(\mathrm{m} / \mathrm{m}_{0}\right)$ for the investigated synthetic FeOx. Top panels show results for P-bearing FeOx (A) and Si-bearing FeOx (B) during acidic dissolution (ADE), bottom panels show results for Pbearing $\mathrm{FeOx}(\mathrm{C})$ and Si-bearing FeOx (D) during reductive dissolution. For 2L-Fh, the dissolution rate curves for the two runs per experiment (ADE or RDE; 4 runs in total, all in duplicate) are shown as dashed lines, the mean of the two runs is shown as black line. Vertical arrows indicate the fraction of each $\mathrm{FeOx}$ that remained at the end of each experiment. 

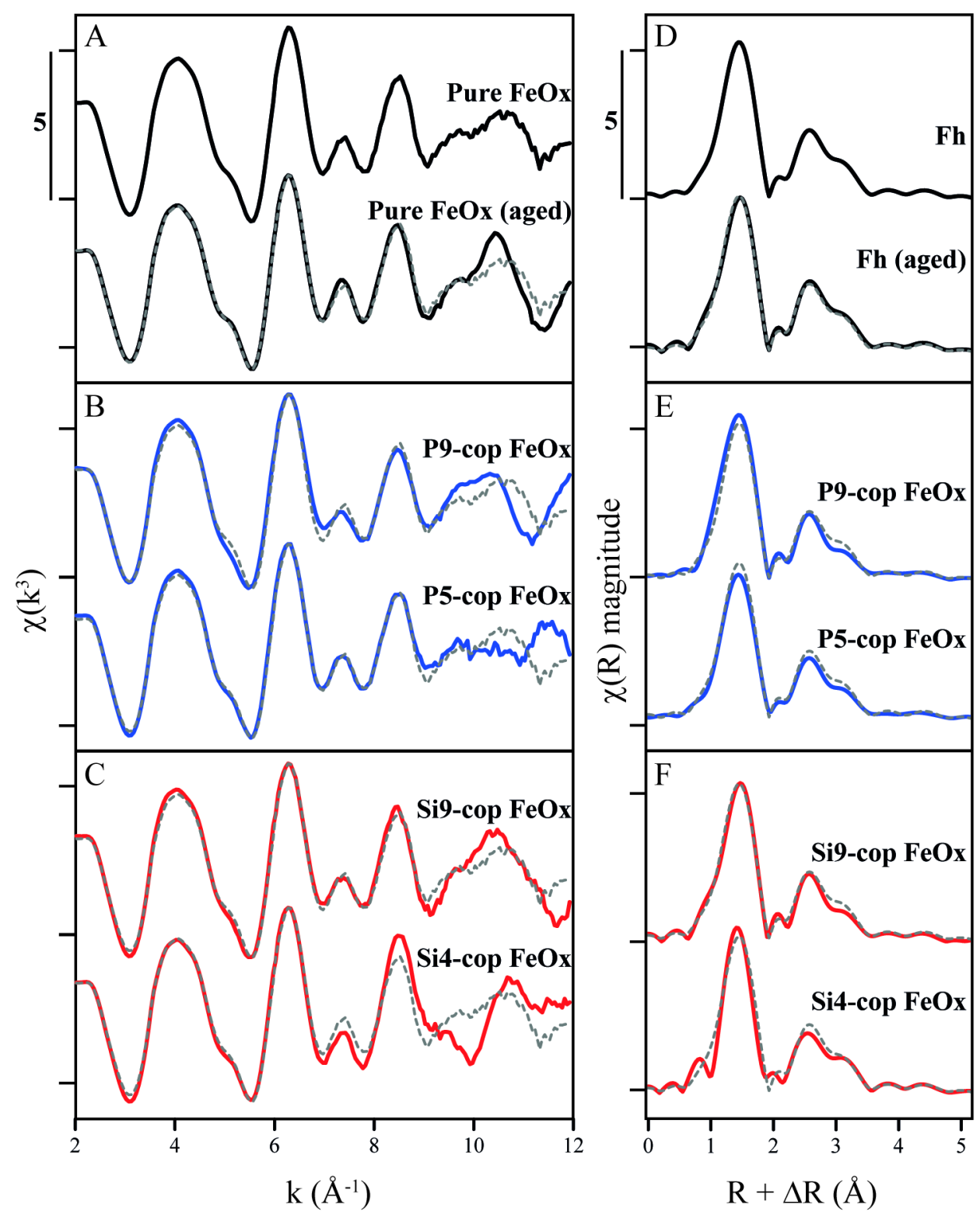

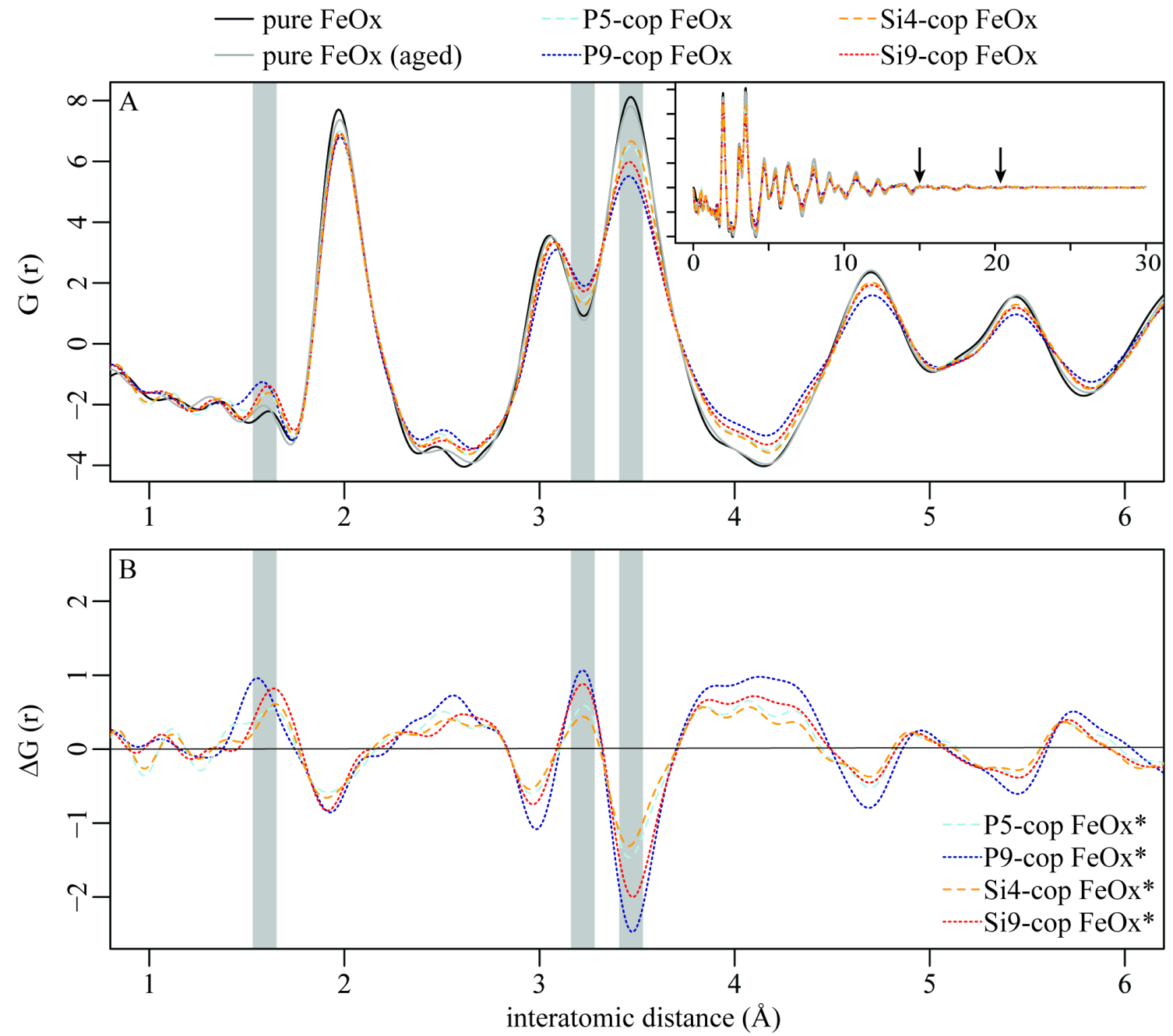
- $\mathrm{Fe}(\mathrm{III})_{\text {dissolved }} \bigcirc \mathrm{Fe}(\mathrm{III})_{\text {colloid }} \bigcirc \mathrm{Fe}(\mathrm{III})_{<0.2 \mu \mathrm{m}} \bigcirc$ dissolved P or Si - molar (Fe/oxyanion) $)_{\mathrm{aq}}$
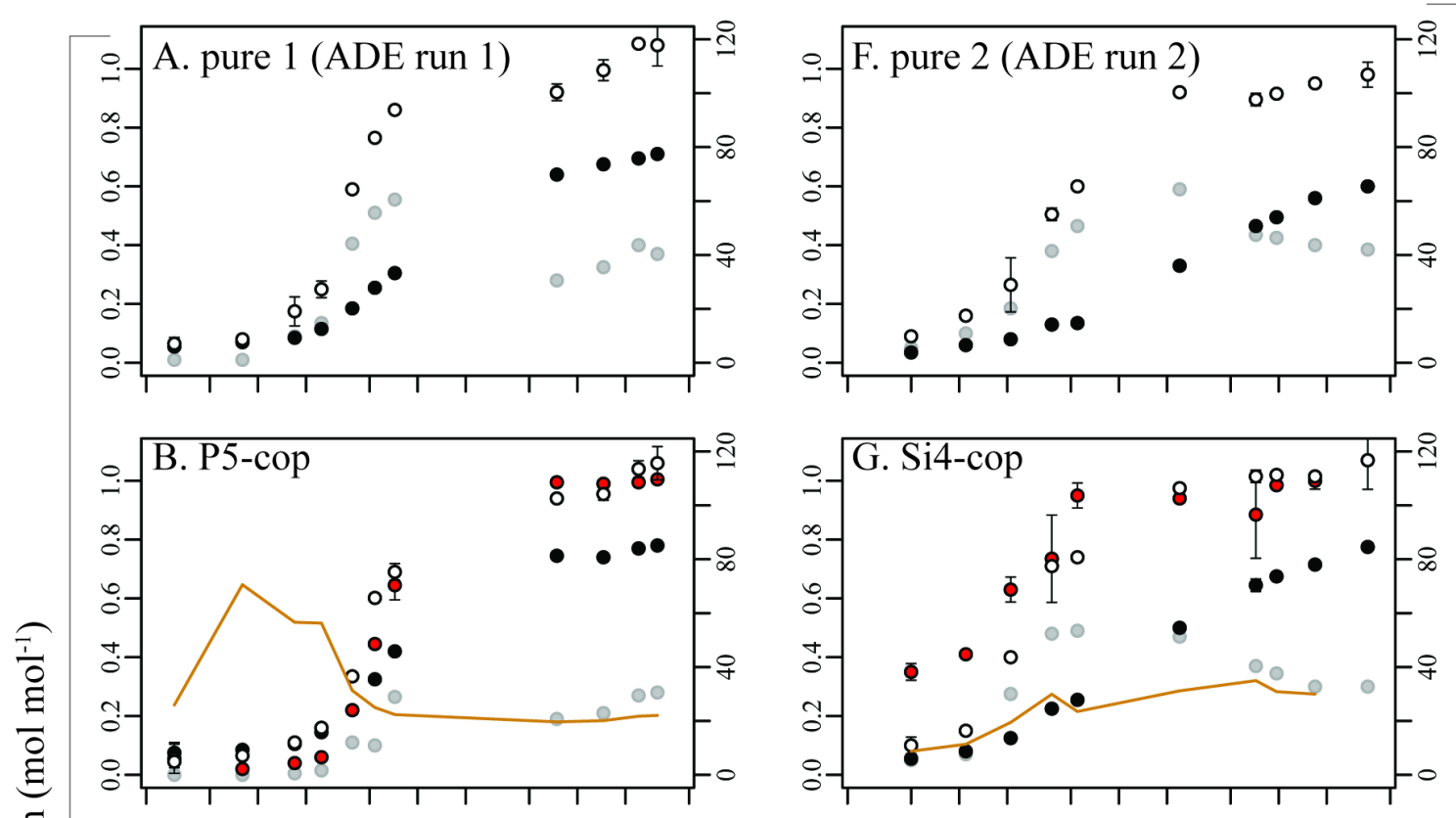

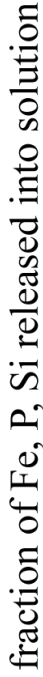
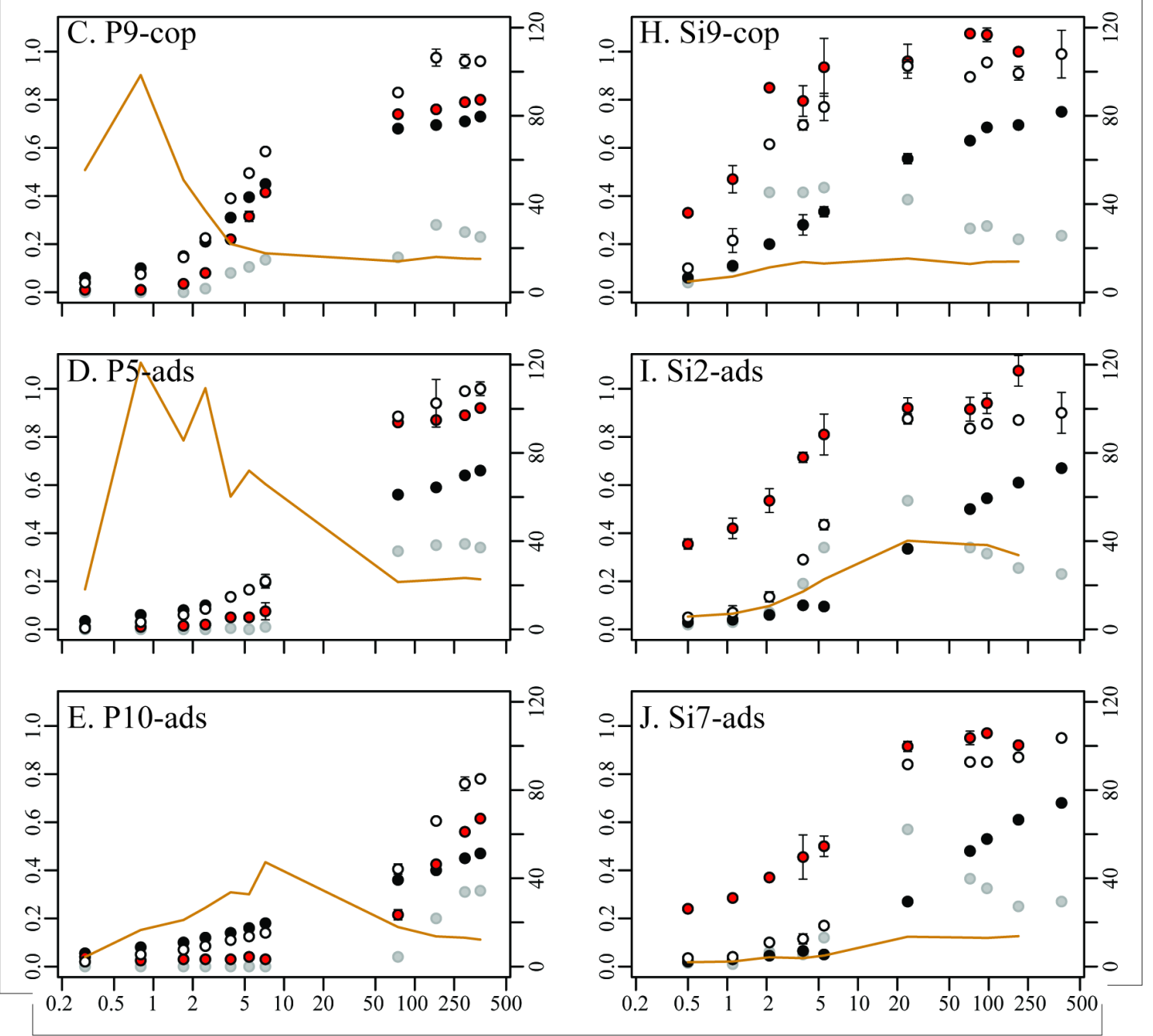

time (hrs) 
- $\mathrm{Fe}(\mathrm{III})_{\text {dissolved }} \bigcirc \mathrm{Fe}_{\text {colloid }} \quad \mathrm{OFe}_{<0.2 \mu \mathrm{m}} \quad$ O dissolved P or Si $\quad$ molar (Fe/oxyanion) aq $_{\text {a }}$

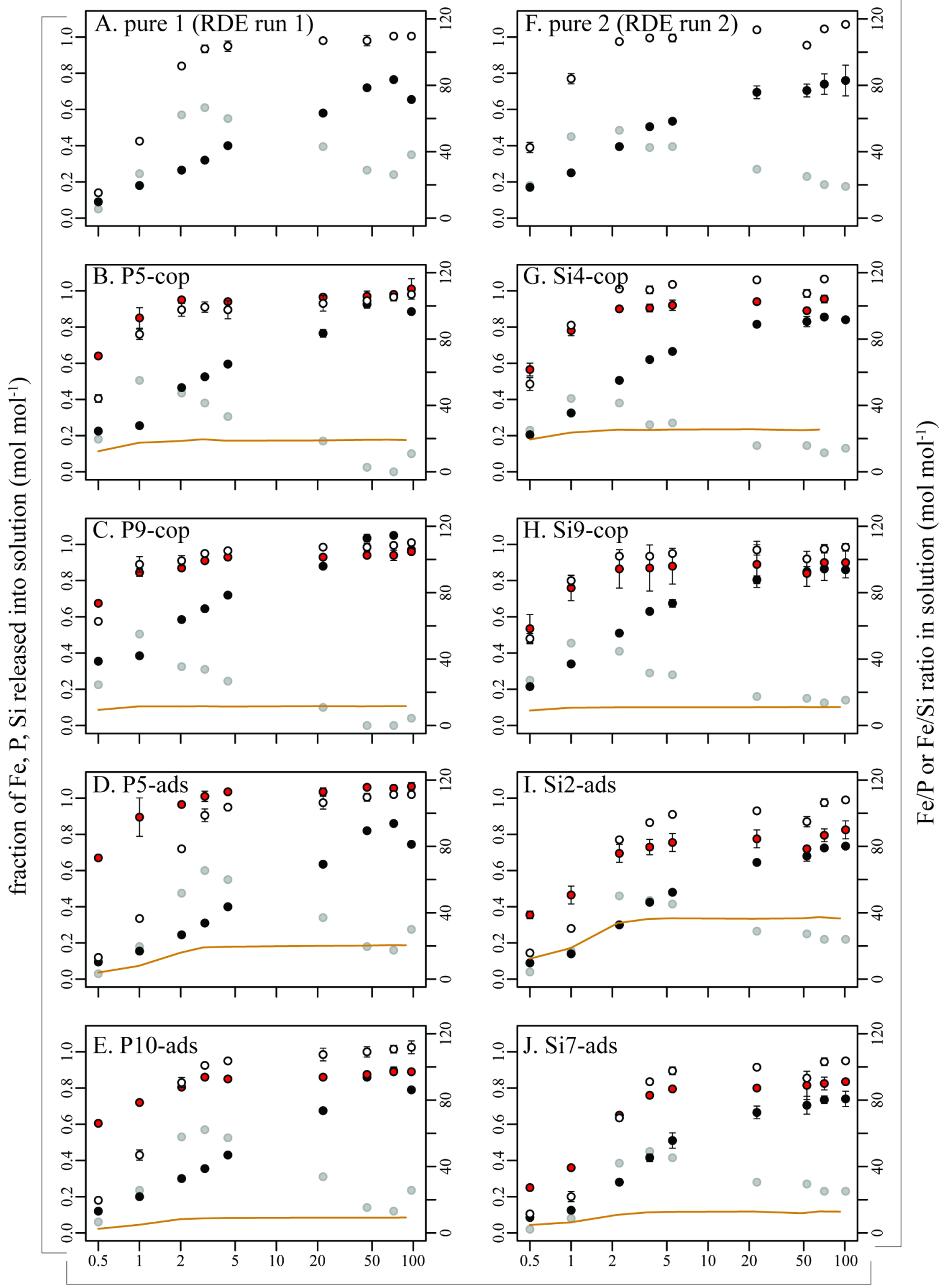

time (hrs) 


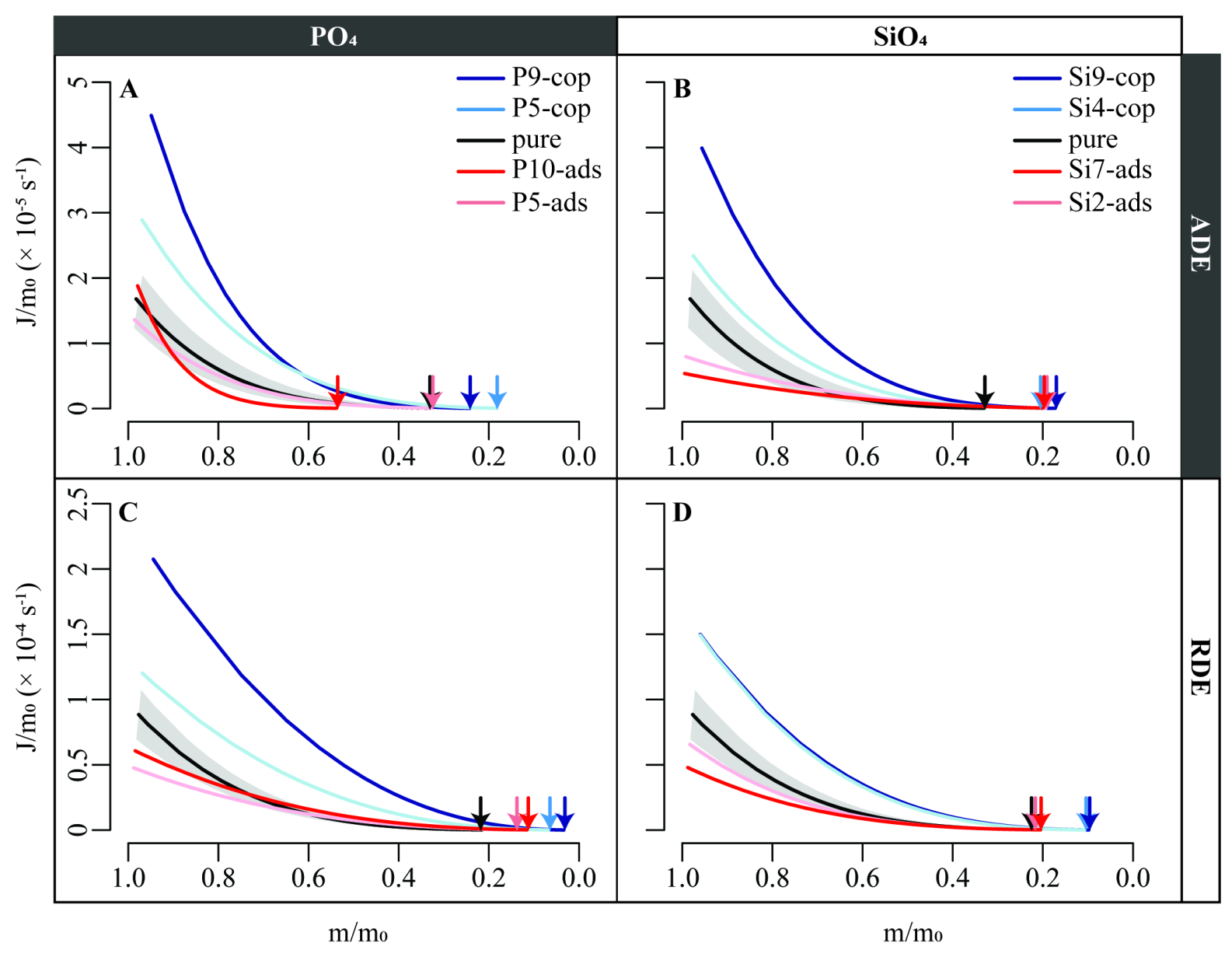


